\title{
N.A.Sirota, M.A.Yaroslarskaya \\ Investigation of active behavioral coping with stress as a mechanism of adaptation / disadaptation to the disease in patients with bronchial asthma
}

\begin{abstract}
Summary
The purpose of the study was to investigate active coping strategies as a mechanism of psychological adaptation / disadaptation to the disease in patients with bronchial asthma $(n=120)$ of 30 to 60 years of age. Psychological investigation was done using the "Ways of Coping Questionnaire". The study has found that protective mechanisms were primarily observed in the personality structure of asthma patients; this could contribute to the development of non-adaptive variants of coping strategies including anger and irritability. The results of this study could be useful for development of educational systems to teach asthma patients coping behavior skills to maintain their health and well-being.

Key words: coping behavior, coping strategies, active behavioral coping with stress, bronchial asthma.
\end{abstract}

\section{Резюме}

Целью исследования было изучение параметров активных видов совладающего со стрессом поведения у больных бронхиальной астмой (БА). В исследовании приняли участие 120 человек в возрасте от 30 до 60 лет. Психологическое исследование проводилось при помощи методики Ways of Coping Questionnaire. В результате было установлено, что в структуре личности больных БА наблюдаются в большей степени защитные механизмы, способствующие формированию неадаптивных вариантов копинг-стратегий, включающих вспышки гнева и раздражения. Полученные результаты позволяют делать предположение о перспективности разработки системы обучения формам совладающего со стрессом поведения больных БА, для поддержания их психического и соматического здоровья.

Ключевые слова: совладающее поведение, копинг-стратегии, активные виды копинга, больные бронхиальной астмой.

Бронхиальная астма (БА) в силу своей большой распространенности и высокого уровня смертности является не только важной медицинской проблемой, но также имеет значительные психологические и социальные последствия для данного контингента больных, что обусловливает комплексный медикопсихологический подход в лечении. Вышеизложенное определяет целесообразность поиска механизмов саморегуляции психической деятельности, ресурсов организма и личности пациента для успешного приспособления к заболеванию и преодоления его последствий. Отдельное место в контексте психологической адаптации пациентов с БА должно занять изучение особенностей поведения, совладающего со стрессом, вызванным болезнью.

Под совладающим поведением понимают особый вид социального поведения субъекта, обеспечивающего или разрушающего его здоровье и благополучие [1]. R.Lazarus определяет копинг-поведение как постоянно меняющиеся когнитивные и поведенческие усилия, затрачиваемые индивидуумом, с целью совладания со специфическими внешними и / или внутренними требованиями, которые оцениваются как чрезмерные или превышающие ресурсы человека [2]. Единого определения и классификации копинг-стратегий не существует. По мнению C.Car- ver et al. [3], адаптивные копинг-стратегии направлены на разрешение проблемной ситуации, например: активные действия, направленные на устранение источника стресса, положительная переоценка ситуации, поиск социальной поддержки. Следующая группа стратегий не связана с активными действиями, но также положительно влияет на адаптацию субъекта в трудной ситуации. Это может быть ожидание подходящих условий для решения проблемы, концентрирование на источнике стресса, снижение активности в отношении других дел и проблем. В 3-ю группу входят неадаптивные стратегии, такие как эмоциональное реагирование в стрессовой ситуации, отрицание произошедшего, избегание разрешения ситуации. Отдельную группу составляют "юмор", "религия", "употребление ПАВ".

За рубежом исследования совладающего поведения при БА проводятся достаточно регулярно [4-10]. Отечественные исследования совладающего поведения больных БА единичны и фрагментарны. БА является дистрессом, эффективность адаптации к которому существенно влияет на течение заболевания, его прогноз, качество жизни и социальное функционирование пациента. Категоризация способов совладания со стрессом, вызванным болезнью, позволит учитывать их при оказании специализированной 
медико-психологической помощи и реализовывать на практике индивидуальный подход к лечению.

Целью настоящего исследования было изучение параметров активных видов совладающего со стрессом поведения у больных БА.

\section{Материалы и методы}

В исследовании приняли участие 120 человек в возрасте от 30 до 60 лет. В 1-ю группу вошли 60 больных, имеющих диагноз БА (шифр по МКБ-10 J45.0J45.9), средний возраст $-47,2 \pm 10,2$ года. Группу сравнения (2-я группа) составили 60 условно здоровых человек, не имеющих заболеваний дыхательных путей, средний возраст $-42,8 \pm 8,7$ года.

Для изучения частоты использования и оценки степени эффективности копинг-стратегий применялся копинг-опросник Ways of Coping Questionnaire (WCQ) R.S.Lazarus, S.Folkman, адаптированный в лаборатории психоневрологического института им. В.М.Бехтерева под руководством Л.И.Вассермана.

При статистической обработке результатов рассчитывались среднеарифметические значения, стандартные отклонения, достоверность различий между группами. Последний показатель рассчитывался по U-критерию Манна-Уитни. При обработке результатов использовалась компьютерная статистическая программа Statistica 6.0 for Windows. Данные считались достоверными при $p \leq 0,05$.

\section{Описание метода WCQ}

Методика WCQ была разработана R.S.Lazarus и S.Folkman в 1988 г. и адаптирована в лаборатории психоневрологического института им. В.М.Бехтерева под руководством Л.И.Вассермана в 2009 г. Опросник включает в себя 50 утверждений, каждое из которых предлагает определенный вариант поведения в затруднительной ситуации.

Участнику исследования дается инструкция: "Вам будет предложен ряд утверждений, касающихся особенностей Вашего поведения в затруднительных ситуациях. Прочитав каждое из утверждений, решите, верно ли оно по отношению к Вам. Вы можете выбрать 4 варианта ответа на этот вопрос в зависимости от того, насколько часто используете указанный способ поведения: 0 - никогда, 1 - редко, 2 - иногда, 3 - часто. Выбранный Вами ответ отметьте в соответствующей графе опросного листа. Будьте внимательны и старайтесь отвечать искренне. Правильных и неправильных ("плохих" и "хороших") ответов здесь нет".

Как следует из инструкции, ответ оценивается испытуемым по 4-балльной шкале в зависимости от частоты обращения к стратегии: никогда -0 баллов, редко - 1 балл, иногда -2 балла, часто -3 балла.

Пункты методики объединены в 8 шкал, соответствующих копинг-стратегий: "Конфронтация", "Дистанцирование", "Самоконтроль", "Поиск социальной поддержки", "Принятие ответственности", "Бегство избегание", "Планирование решения проблемы", "Положительная переоценка".

\section{Обработка и интерпретация результатов}

Степень предпочтительности стратегии определяется по шкале Т-баллов при М (среднем значении по стандартной шкале) равном 50 Т-баллам и $\sigma$ (стандартном отклонении) равном 10 Т-баллам.

Для определения "сырых" показателей по шкалам методики вычисляется сумма показателей по утверждениям, входящим в каждую из шкал, с учетом соотношения между ответом и начисляемыми баллами.

После расчета "сырых" значений по шкалам осушествляется их перевод в стандартные Т-баллы. Для определения стандартного показателя необходимо соотнести "сырой" балл со значениями нормативной группы с учетом пола и возраста.

Степень предпочтительности для испытуемого стратегии совладания со стрессом определяется на основании следующих нормативов:

1. Показатель $<40$ баллов - редкое использование стратегии.

2. Показатель от 40 до 60 баллов - умеренное использование соответствующей стратегии.

3. Показатель $>60$ баллов - выраженное предпочтение соответствующей стратегии.

\section{Результаты и обсуждение}

\section{Шкала "Конфронтация"}

Средние показатели для обследованных групп представлены на рисунке. Больные БА достоверно чаще прибегают к использованию копинг-стратегии "Конфронтация", по сравнению со здоровыми испытуемыми $(p=0,01)$. Средние показатели для 1-й группы составили $-53,7 \pm 11,4$, для 2-й группы $-47,1 \pm$ 10,4. Активное обращение к конфронтации больными БА может нести в себе как положительные, так и негативные стороны. С одной стороны, больным БА предоставляется возможность при использовании конфронтации активно противостоять трудностям, дать выход накопившимся негативным эмоциям. Однако активно и эффективно противостоять трудностям можно лишь в случае, когда источник стресса -

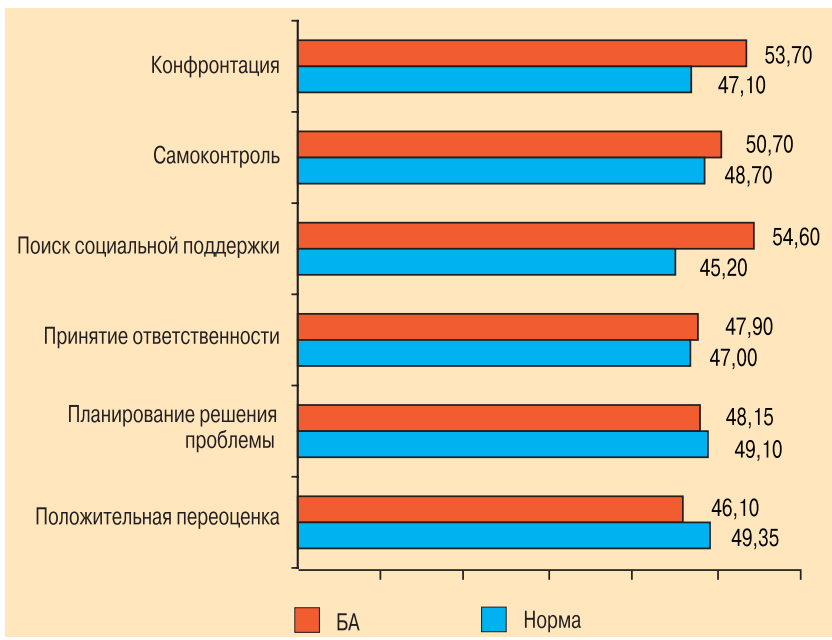

Рисунок. Средние показатели предпочтительности стратегий преодолевающего стресс поведения для больных БА и здоровых испытуемых, полученные с помощью методики WCQ 
реальный объект и при соответствующей ситуации. Таким образом, агрессия имеет четкую направленность, т. е. копинг помогает в управлении стрессом. Зачастую больные БА, особенно гормонозависимые в период обострения, испытывают негативные эмоции вследствие изменения гормонального фона, ощущения дискомфорта как физического, так и психологического, неустойчивой самооценки, и вследствие вышеперечисленного как бы "срываются" на коллегах по работе, друзьях, семье и других, т. е. сами создают или усугубляют конфликтную ситуацию. Враждебность в данном случае не персонифицирована, она не целенаправленна, не рационально обоснованна, а становится результатом временной разрядки эмоционального напряжения, т. к. сама по себе стрессовая ситуация не решается, а обостряется.

\section{Шкала "Самоконтроль"}

Средние значения по шкале "Самоконтроль" у больных БА варьируются в пределах 50,7 $\pm 8,4$, у группы сравнения $-48,7 \pm 10,25$ (рисунок). Надежных различий в обращении к копингу между пациентами 1 -й и 2-й группы не найдено $(p>0,05)$. Обе группы эффективно используют стратегию "Самоконтроль", что позволяет пациентам выбирать более желаемые паттерны поведения.

\section{Шкала "Поиск социальной поддержки"}

Больные БА достоверно активнее используют стратегию "Поиск социальной поддержки" по сравнению со здоровыми испытуемыми ( $p=0,000)$ (рисунок). Средние баллы у пациентов с БА составили $-54,6 \pm$ 7,45 , в группе сравнения - 45,2 $\pm 10,7$. Возможно, это связано с осознанием необходимости в получении медицинской помощи, с ограничением деятельности в период обострения заболевания, а также с ощущением потребности в социальной поддержке.

\section{Шкала "Принятие ответственности"}

Надежных различий в использовании стратегии "Принятие ответственности" у пациентов, страдающих БА, и в группе сравнения выявлено не было ( $p>$ $0,05)$ (рисунок). Средние значения у лиц, имеющих диагноз БА, составили 47,9 \pm 9,02, у здоровых испытуемых $-47 \pm 10,7$.

\section{Шкала "Планирование решения проблемы"}

Средние баллы у пациентов, страдающих БА, составили $-48,15 \pm 9,4$, в группе сравнения $-49,1 \pm 9,7$ $(p=0,000)$ (рисунок). Достоверных различий между пациентами 1-й и 2-й группы не было выявлено ( $p>$ $0,05)$, в обеих выборках значения укладываются в интервал 40-60 Т-баллов, что указывает на умеренное обращение к стратегии.

\section{Шкала "Положительная переоценка"}

Средние показатели в группе БА варьируются в пределах 46,1 \pm 10,5, у здоровых испытуемых $-49,35 \pm$ 9,97 (рисунок). Надежных различий в обращении к копингу между пациентами 1-й и 2-й группы выявлено не было $(p>0,05)$. Полученные данные свиде- тельствуют о том, что обе выборки умеренно обращаются к мысленному моделированию своих высказываний, поступков, а так же произошедших ситуаций.

\section{Заключение}

1. Больные БА в стрессовых ситуациях чрезмерно используют копинг-стратегию "Конфронтация".

2. Враждебность пациентов с БА не персонифицирована, она становится результатом временной разрядки эмоционального напряжения, т. к. сама по себе стрессовая ситуация не решается, а обостряется.

3. Активное использование стратегии "Поиск социальной поддержки" больными БА может быть связано с осознанием необходимости получения медицинской помощи, с ограничением деятельности в период обострения заболевания, а так же с ощущением потребности в самой социальной поддержке.

\section{Литература}

1. Крюкова Т.Л. Человек как субъект совладающего поведения. В кн.: Журавлев А.Л., Крюкова Т.Л., Сергиенко Е.А. (ред.). Совладающее поведение: Современное состояние и перспективы. М.: Изд-во Института психологии РАН; 2008. 55-66.

2. Losoya S., Eisenberg N., Fabes R.A. Developmental issues in the study of coping. Int. J. Behav. Dev., 1998; 22 (2): 287-313.

3. Carver C.S., Scheier M.F., Weintraub J.K. Assessing coping strategies: a theoretically based approach. J. Person. Soc. Psychol. 1989; 56: 267-283.

4. Lavoie K.L., Bouthillier D., Bacon S.L. et al. Psychologic distress and maladaptive coping styles in patients with severe vs moderate asthma. Chest 2010; 137 (6): 1324-1331.

5. Grineski S. Coping with asthma in the central city: parental experiences with children's health care. J. Hlth Care Poor Underserv. 2008; 19 (1): 227-236.

6. Hesselink A., Penninx B., Schlosser M. et al. The role of coping resources and coping style in quality of life of patients with asthma or COPD. Quality Life Res. 2004; 13: 509-518.

7. Lima L., Guerra M.P., de Lemos M.S. The psychological adjustment of children with asthma: study of associated variables. Spanish J. Psychol. 2010; 13 (1): 353-363.

8. Kaptein A.A., Klok T., Moss-Morris R., Brand P.L. Illness perceptions: impact on self-management and control in asthma. Curr. Opin. Allergy Clin. Immunol. 2010; 10 (3): 194-199.

9. Rydstrom I, Hartman J, Segesten K. Not letting the disease get the upper hand over life: strategies of teens with asthma. Scand. J. Caring Sci. 2005; 19 (4): 388-395.

10. Fley G., Beier J. Coping strategies of children with asthma. Testing the applicability of the German version of the Schoolagers' Coping Strategies Inventory (SCSI). Pflege 2006; 19 (1): 4-10.

\section{Информация об авторах}

Сирота Наталья Александровна - д. м. н., проф., декан факультета клинической психологии, зав. кафедрой клинической психологии Московского городского медико-стоматологического университета; тел.: (495) 389-16-54, факс: (495) 389-16-54; e-mail: sirotan@mail.ru

Ярославская Мария Александровна - аспирант кафедры клинической психологии Московского государственного медико-стоматологического университета, медицинский психолог; тел.: (499) 193-04-00, (499) 193-55-77; e-mail: visiteuse@mail.ru 